\section{RIGHT VENTRICULAR FUNCTION EVALUATED BY VOLUMETRIC ANALYSIS DURING LEFT HEART BYPASS IN A CANINE MODEL OF POSTISCHEMIC CARDIAC DYSFUNCTION}

Right ventricular function during left heart bypass was evaluated by volumetric analysis with a conductance catheter in 12 dogs with postischemic cardiac dysfunction. The conductance catheter was used to assess the volumetric status of the right ventricle and thereby allowed a right ventricular pressure-volume curve to be obtained, in which transient volume loading on the right ventricle was applied. The following right ventricular properties during left heart bypass were assessed and compared with properties measured without left heart bypass, by means of load-independent parameters: maximum elastance, stroke work/end-diastolic volume relation, end-diastolic pressure/volume relation, and stroke work/end-diastolic pressure relation. The stroke volume derived from the conductance catheter and the electromagnetic flow probe showed good linear correlation $\left(r^{2}=\mathbf{0 . 7 3 3}\right.$ to 0.975$)$. After initiation of left heart bypass, maximum elastance did not change significantly, although volume intercept significantly increased, from $1.2 \pm 7.3$ to $3.6 \pm 7.9 \mathrm{ml}(p<0.05)$. End-diastolic pressure/ volume relation was well fitted to the exponential curve $\left(\mathrm{EDP}=\mathrm{e}^{(\mathrm{k1} \cdot \mathrm{EDV}+\mathrm{k2})}\right.$ ) and was shifted to the right and downward during left heart bypass; the slope $\mathrm{k} 1$ significantly decreased, from $0.12 \pm 0.06$ to $0.10 \pm 0.07(p<0.01)$. Stroke work/end-diastolic volume relation and stroke work/end-diastolic pressure relation were closely fitted to the linear regression, and their slopes were significantly increased during left heart bypass, from $0.14 \pm 0.08$ to $0.18 \pm 0.08(p<0.05)$ and from $0.22 \pm 0.15$ to $0.34 \pm 0.19(p<0.01)$, respectively. These results suggest that the decompression of the left ventricle and septal shifting by left heart bypass provide good diastolic compliance and good systolic performance because of afterload unloading of the right ventricle. Thus the left heart bypass improved the overall right ventricular performance, particularly at higher end-diastolic pressures, in dogs with postischemic cardiac dysfunction. (J THORAC Cardiovasc Surg 1995;109:796-803)

Mitsuru Kitano, MD, Kazunobu Nishimura, MD, PhD, Park Chan Hee, MD, Yoshifumi Okamoto, MD, PhD, and Toshihiko Ban, MD, PhD, Kyoto, Japan
Qince left ventricular (LV) assist was initially applied for intractable cardiac failure in human beings, ${ }^{1}$ the use of left heart bypass (LHB) has been widely accepted in patients who cannot be weaned from cardiopulmonary bypass, ${ }^{2}$ for postinfarction cardiogenic shock ${ }^{3}$ and, more recently, as a bridge to heart transplantation. ${ }^{4}$ One of the several problems related to LHB is right ventricular (RV) failure during LHB, which has been reported in approximately $20 \%$ to $25 \%$ of LHB cases. ${ }^{5-8}$ A number of

From the Department of Cardiovascular Surgery, Kyoto University Faculty of Medicine, Kyoto, Japan.

Received for publication Jan. 20, 1994.

Accepted for publication August 4, 1994.

Address for reprints: Mitsuru Kitano, MD, Department of Cardiovascular Surgery, Takeda Hospital, Higashiiru ShiokojidoriNishinotoin, Shimogyo-ku, Kyoto 600, Japan.

Copyright (C) 1995 by Mosby-Year Book, Inc.

$0022-5223 / 95 \$ 3.00+0 \quad \mathbf{1 2 / 1 / 5 9 6 2 0}$ investigations concerning this problem have been performed. According to previous studies, the increased venous return caused by LHB should affect RV function to some extent, and in patients with elevated pulmonary vascular resistance caused by obstructive vascular disease or emboli, an elevated venous return produced by $\mathrm{LHB}$ could result in greater RV afterload. ${ }^{6}$ However, the cause of RV failure during LHB remains unclear. LHB itself might mechanically impair RV function or might merely unmask preexisting right heart failure.

A major factor accounting for these conflicting results may be the difficulty in measuring RV volume because of its complex geometry and asymmetric contraction. In almost all previous studies, RV volume has been calculated by length or area as measured by means of ultrasonic crystals or echocardiography. These variables are too inaccurate to describe the RV function.

We therefore used a conductance catheter to 
measure RV volume more accurately to clarify the direct effects on RV function of LV unloading and septal shifting during LHB. Because the conductance catheter allows instantaneous volumetric measurements, we were able to detect subtle changes of hemodynamics during LHB. To reflect more accurately the geometric change of the RV during LHB, we adopted the volume loading method rather than the caval occlusion method. To simulate clinical conditions, we used a model of postischemic cardiac dysfunction, which was produced by transient occlusion of the ascending aorta. ${ }^{9}$

\section{Methods}

Twelve mongrel dogs $(15.1 \pm 1.8 \mathrm{~kg})$ were used in this study. The dogs were premedicated with ketamine hydrochloride $(10 \mathrm{mg} / \mathrm{kg})$ and anesthetized with pentobarbital sodium (initial bolus of $20 \mathrm{mg} / \mathrm{kg}$ followed by continuous infusion of $2 \mathrm{mg} / \mathrm{kg}$ ). They were intubated and their lungs were mechanically ventilated. Bilateral thoracotomy via transection of the sternum was performed. After pericardiotomy, the heart was suspended in a pericardial cradle.

A conductance catheter equipped with eight electrodes spaced at $8 \mathrm{~mm}$ intervals (Cordis, Europa NV, Roden, The Netherlands) was placed in the RV through the main pulmonary artery and connected to a volumetric system (Sigma 5, Leycom, Oegstgeest, The Netherlands). With this apparatus, RV conductance was measured and converted to $R V$ volume. The final position of the catheter in the RV, with the most distal electrode placed near the apex and the most proximal electrode just cephalad to the pulmonary valve, was determined by the monitor findings. These findings showed five consecutive segmental pressure-volume loops during the experiment, as confirmed on postmortem examination. An electromagnetic flow probe (FB type, Nihon Koden, Tokyo, Japan) was also placed around the main pulmonary artery in three dogs to investigate the relationship of the volume measured with the flow probe to that measured with the conductance catheter. RV pressure was measured with a cathetertipped manometer (TCP2, Toyoda, Aichi, Japan) through the main pulmonary artery. Arterial pressure, LV pressure, and right atrial pressure were measured with fluidfilled catheters. The signals from the electrocardiogram and for RV pressure and $\mathrm{RV}$ volume were entered into a computer (PC-9801, NEC Corp., Tokyo, Japan), by which pressure-volume loops were drawn in real time. Two withdrawal cannulas, which were inserted into the left atrium and the LV through the apex for full venting from the LV, were connected to a centrifugal pump (BioConsole 540, Medtronic Bio-Medicus, Eden Prairie, Minn.) by means of a $\mathrm{Y}$ connector. The return cannula was applied into the left subclavian artery. The entire design is illustrated in Fig. 1.

A reservoir containing lactated Ringer's solution was attached to the right atrium for volume loading. So that the conductance of circulatory blood could be maintained, blood and solution were fully mixed by a recirculation system before measurement. The conductance of the

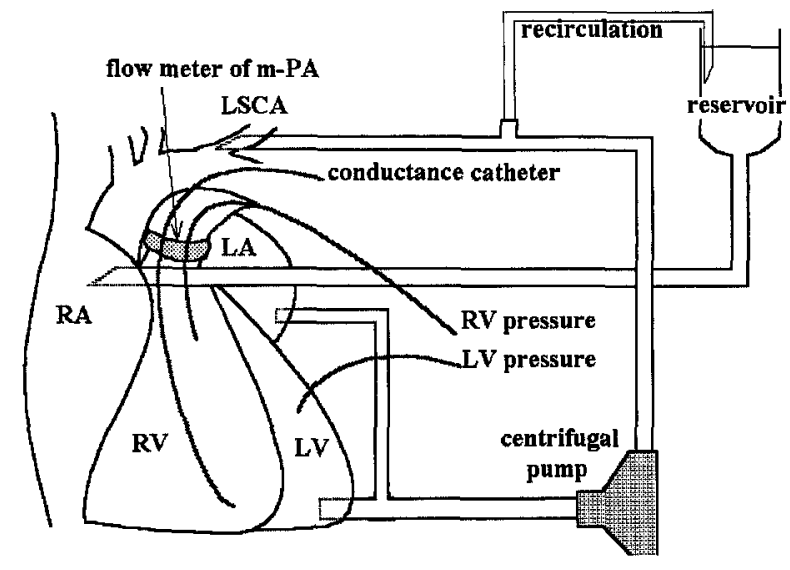

Fig. 1. Diagram of experimental preparation. Transient volume load from the right atrial reservoir was added to change right ventricular end-diastolic pressure. $L A$, Left atrium; $L S C A$, left subclavian artery; $L V$, left ventricle; $m-P A$, main pulmonary artery; $R A$, right atrium; $R V$, right ventricle.

mixed circulating blood was measured and corrected in the Sigma 5 volumetric system in each measurement. Correction volume, which accounts for the conductance of the tissues surrounding the RV cavity, was measured by injection of hypertonic salt solution ( $10 \%$ sodium chloride) and then subtracted from the recorded volume. ${ }^{10}$

The postischemic model was produced by occlusion of the ascending aorta for approximately 15 minutes during LHB. Measurement was started about 5 minutes after unclamping of the aorta. After baseline measurements (no volume loading) of 10 seconds in duration with and without LHB, volume loading measurements for a 12second recording period were performed both with and without LHB. Volume loading from the reservoir was rapidly applied for a 12 -second recording period. RV end-diastolic pressure subsequently increased from approximately 3 to $10 \mathrm{~mm} \mathrm{Hg}$. Soon after the volume was returned to the reservoir, LHB was started and volume loading measurements were then repeated after a stabilization period of 1 to 2 minutes under LHB. Any recordings that were obtained during such conditions as unstable ventricular pressure or electrocardiographic evidence of arrhythmia were excluded. Hemodynamic measurements during the nonsupported state were collected again after all experimental protocols to ascertain that the condition was unchanged.

All animals received humane care in compliance with the "Principles of Laboratory Animal Care" formulated by the National Society for Medical Research and the "Guide for the Care and Use of Laboratory Animals" prepared by the National Academy of Sciences and published by the National Institutes of Health (NIH Publication No. 80-23, revised 1978).

Data analysis. The signals in the Sigma 5 system for the electrocardiogram, RV pressure, and conductance-derived $R V$ volume were digitized at $3 \mathrm{msec}$ intervals, and all signals were simultaneously recorded on a digital data recorder 
LHB $(-)$
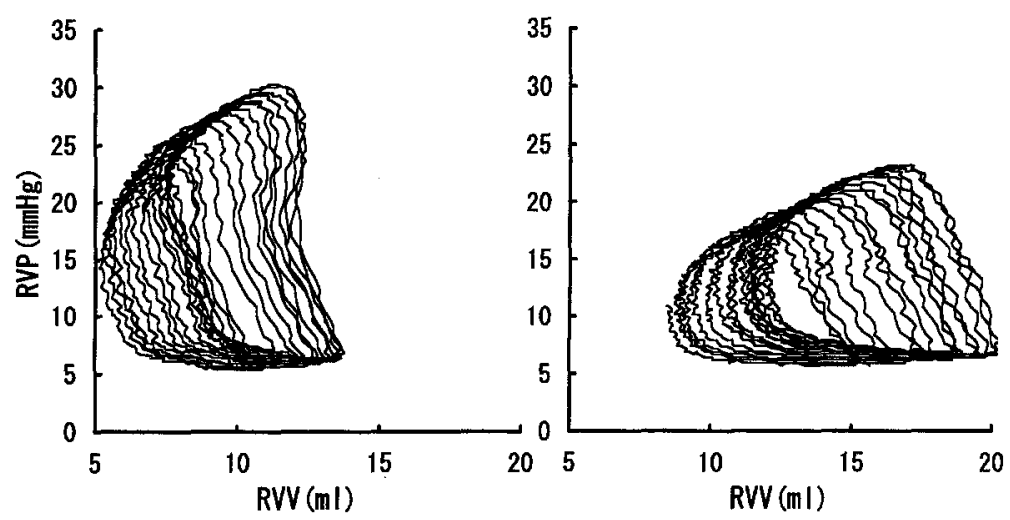

Fig. 2. Right ventricular pressure-volume loops obtained by changing preload. $L H B(-)$, Without left heart bypass; $L H B(+)$, with left heart bypass; $R V P$, right ventricular pressure; $R V$, right ventricular volume by conductance catheter.

(RD-111T, TEAC, Tokyo, Japan) and a thermal recorder (RTA-1300, Nihon Koden, Tokyo, Japan). All digitized data were stored on floppy disks and subsequently analyzed with a computer (PC-9801, NEC Corp., Tokyo, Japan). The RV end-diastolic point was determined at the beginning of rapid upswing of the RV pressure curve over every cardiac cycle. The stroke volume was calculated by subtracting the minimum conductance-derived value from the maximum value for each cardiac cycle, and stroke work was calculated as the integral of the instantaneous pressure-volume loop for each cardiac cycle. Each cardiac cycle was determined as the interval between $R$ waves of the electrocardiogram. RV function was assessed by means of the following four loadindependent parameters: maximum elastance (Emax) as ejecting function; end-diastolic pressure/volume relation as diastolic function; stroke work/end-diastolic volume relation as systolic performance; and stroke work/end-diastolic pressure relation as overall $\mathrm{RV}$ performance.

Emax was determined by an iterative method that computed the best-fit tangent with the pressure-volume loops created during transient volume loading. ${ }^{11}$ The slope Emax and intercept $V_{0}$ were estimated by linear regression analysis as follows:

$$
\mathrm{ESP}=\mathrm{Emax} \times\left(\mathrm{ESV}-\mathrm{V}_{0}\right)
$$

where ESP is end-systolic pressure and ESV is endsystolic volume. End-diastolic pressure/volume relation was fitted to the following exponential curve:

$$
\mathrm{EDP}=\mathrm{e}^{\left(\mathrm{k}^{1} \cdot \mathrm{EDV}+\mathrm{k}^{2}\right)}
$$

where EDP is end-diastolic pressure, EDV is end-diastolic volume, and $\mathrm{k}_{1}$ and $\mathrm{k}_{2}$ are determined by a least squares technique. The end-diastolic volumes calculated by this formula at a given end-diastolic pressure were averaged. Stroke work/end-diastolic volume relation was derived by linear regression analysis as follows:

$$
\mathrm{SW}=\mathrm{R}(\mathrm{s}) \times\left[\mathrm{EDV}-\mathrm{V}_{0}(\mathrm{~s})\right]
$$

where SW is stroke work and $V_{0}(s)$ is volume intercept. The slope R(s) and stroke work values at a given enddiastolic volume were averaged. Stroke work/end-diastolic pressure relation was also derived by linear regression analysis as follows:

$$
\mathrm{SW}=\mathrm{R}(\mathrm{t}) \times\left[\mathrm{EDP}-\mathrm{P}_{0}(\mathrm{t})\right]
$$

where $P_{0}(t)$ is pressure intercept. The slope $R(t)$ and stroke work values at a given end-diastolic pressure were averaged.

All results shown are expressed as means \pm standard deviation, and $r^{2}$ indicates correlation coefficient. Statistical comparisons between data obtained without and with LHB were performed with a paired $t$ test. A $p$ value of less than 0.05 was considered to be significant.

\section{Results}

Fig. 2 shows representative tracings of the RV pressure-volume loops with and without LHB. In preliminary studies, the conductance-derived stroke volume was compared with that measured by the electromagnetic flow probe in three dogs with intact hearts (Fig. 3). The two stroke volumes showed high correlation (linear regression, $r^{2}=0.733$ to 0.975 ). Table I shows RV hemodynamic variables of basal state and load-independent parameters by volume loading from seven dogs compared before and after ischemic conditions caused by aortic clamping. During the basal state, RV stroke work and RV stroke volume were significantly less in the dogs with postischemic dysfunction $\left(0.6 \pm 0.5 \times 10^{5} \mathrm{erg}, 3.2 \pm\right.$ $1.0 \mathrm{ml})$ than in those with preischemic hearts $(1.2 \pm$ $0.7 \times 10^{5} \mathrm{erg}, 5.6 \pm 2.1 \mathrm{ml}$ ). Furthermore, in load-independent parameters by the volume loading 

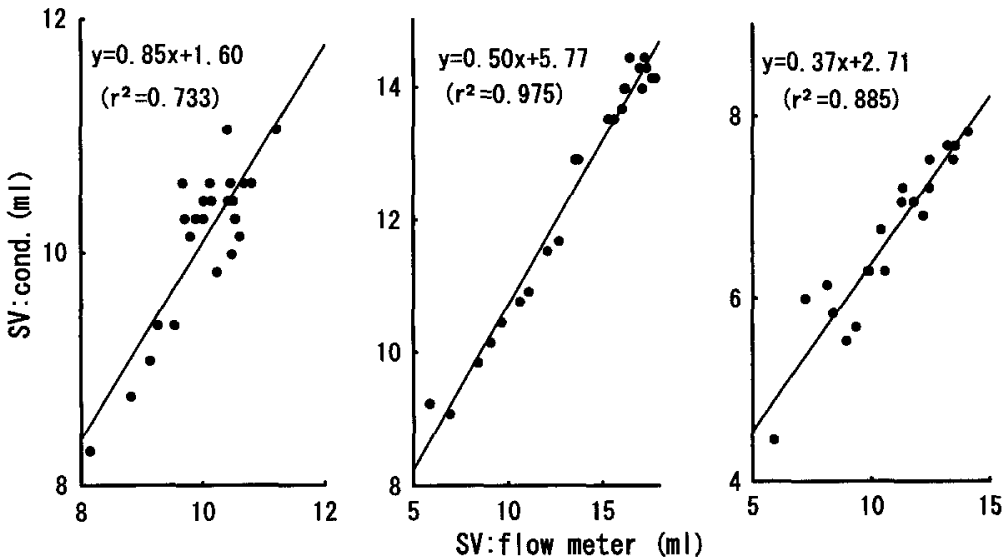

Fig. 3. Simultaneous measurement of stroke volume calculated from conductance ( $S V$ :cond.) versus that calculated from electromagnetic flow probe (SV:flow meter) in three dogs.

Table I. Comparisons of basal state hemodynamic variables and load-independent parameters between preischemic and postischemic dysfunction

\begin{tabular}{lcc}
\hline & $\begin{array}{c}\text { Before } \\
\text { ischemic } \\
\text { dysfunction }\end{array}$ & $\begin{array}{c}\text { After } \\
\text { ischemic } \\
\text { dysfunction }\end{array}$ \\
\hline Hemodynamic variables of basal state $(n=7)$ & \\
RVSW ( $\times 10^{5}$ erg) & $1.2 \pm 0.7$ & $0.6 \pm 0.5^{*}$ \\
RVSV (ml) & $5.6 \pm 2.1$ & $3.2 \pm 1.0 \dagger$ \\
Systolic RVP (mm Hg) & $24.0 \pm 5.4$ & $22.0 \pm 9.6$ \\
RVEDV (ml) & $13.6 \pm 4.8$ & $12.7 \pm 4.1$ \\
RVEDP (mm Hg) & $3.6 \pm 1.0$ & $4.2 \pm 1.5$ \\
Systolic LVP (mm Hg) & $97.3 \pm 18.7$ & $73.7 \pm 36.7$ \\
Heart rate (beats/min) & $141.6 \pm 17.0$ & $127.7 \pm 12.8$ \\
Load-independent parameters $(n=7)$ & \\
Emax & $2.44 \pm 0.61$ & $2.03 \pm 0.41^{*}$ \\
V & $-0.39 \pm 7.55$ & $1.04 \pm 6.00$ \\
EDP/VR ( $\left.\mathbf{k}_{1}\right)$ & $0.08 \pm 0.04$ & $0.12 \pm 0.03$ \\
SW/EDVR [R(s)] & $0.22 \pm 0.13$ & $0.15 \pm 0.08 \dagger$ \\
SW/EDPR [R(t)] & $0.56 \pm 0.36$ & $0.21 \pm 0.11 \dagger$ \\
\hline
\end{tabular}

All values are mean \pm standard error of the mean. $R V S W$, Right ventricular stroke work; $R V S V$, right ventricular stroke volume; $R V P$, right ventricular pressure; $R V E D V$, right ventricular end-diastolic volume; $R V E D P$, right ventricular end-diastolic pressure; $L V P$, left ventricular pressure; Emax, slope of maximum elastance; $V_{0}$, volume intercept of Emax; $E D P / V R$, end-diastolic pressure/volume relation; $k_{b}$ slope of enddiastolic pressure/volume relation; $S W / E D V R$, stroke work/end-diastolic volume relation; $R(s)$, slope of stroke work/end-diastolic volume relation; $S W / E D P R$, stroke work/end-diastolic pressure relation; $R(t)$, slope of stroke work/end-diastolic pressure relation.

$* p<0.01$.

$\dagger p<0.05$.

method, the slopes of Emax, stroke work/end-diastolic volume relation, and stroke work/end-diastolic pressure relation were significantly impaired (from $2.44 \pm 0.61$ to $2.03 \pm 0.41$, from $0.22 \pm 1.13$ to $0.15 \pm 0.08$, and from $0.56 \pm 0.36$ to $0.21 \pm 0.11$, respectively).
Table II. Hemodynamic variables of basal state before volume loading

\begin{tabular}{lcc}
\hline \multicolumn{1}{c}{ Variables $(\mathrm{n}=12)$} & LHB $(-)$ & LHB (+) \\
\hline RVSW $\left(\times 10^{5} \mathrm{erg}\right)$ & $0.9 \pm 0.6$ & $0.9 \pm 0.6$ \\
RVSV (ml) & $4.1 \pm 2.0$ & $5.4 \pm 1.9^{*}$ \\
Systolic RVP (mm Hg) & $22.6 \pm 7.6$ & $20.3 \pm 9.0 \dagger$ \\
RVEDV (ml) & $13.3 \pm 4.1$ & $14.9 \pm 4.2 \dagger$ \\
RVEDP (mm Hg) & $4.2 \pm 1.8$ & $4.1 \pm 1.9$ \\
Systolic LVP (mm Hg) & $77.3 \pm 33.2$ & $18.2 \pm 20.0 \ddagger$ \\
Heart rate (beats/min) & $136.7 \pm 22.3$ & $129.8 \pm 21.0$
\end{tabular}

All values are mean \pm standard error of the mean. $L H B(-)$, Without left heart bypass; $L H B(+)$, with left heart bypass; $R V S W$, right ventricular stroke work; $R V S V$, right ventricular stroke volume; $R V P$, right ventricular pressure; $R V E D V$, right ventricular end-diastolic volume; $R V E D P$, right ventricular end-diastolic pressure; $L V P$, left ventricular pressure.

${ }^{*} p<0.01$ with paired $t$ test between LHB (-) and LHB $(+)$.

$\dagger p<0.05$ with paired $t$ test between LHB (-) and LHB $(+)$.

$\ddagger p<0.001$ with paired $t$ test between LHB $(-)$ and LHB $(+)$.

Table II is a summary of the average steady-state hemodynamic variables before volume loading without and with LHB from the 12 postischemic studies. Pump flow rate during full LV assist averaged $90.3 \pm 27.1 \mathrm{ml} / \mathrm{kg}$ per minute, and the $\mathrm{LV}$ peak pressure was decreased from $77.3 \pm 33.2$ to $18.2 \pm$ $20.0 \mathrm{~mm} \mathrm{Hg}(p<0.001)$ by full venting. The RV stroke volume and RV end-diastolic volume were significantly increased $(p<0.01$ and $p<0.05$, respectively). The peak RV pressure decreased ( $p<$ 0.05 ), whereas RV stroke work and RV end-diastolic pressure did not significantly change. Table III shows the averaged load-independent parameters with and without LHB. The slope of Emax showed no significant change, but $\mathrm{V}_{0}$ significantly increased from $1.2 \pm 7.3$ to $3.6 \pm 7.9 \mathrm{ml}(p<0.05)$ under LHB. The end-diastolic pressure/volume relation 
Table III. RV function expressed by loadindependent parameters

\begin{tabular}{|c|c|c|}
\hline $\begin{array}{l}\text { Variables } \\
(\mathrm{n}=12)\end{array}$ & $L H B(-)$ & $L H B(+)$ \\
\hline Emax & $1.92 \pm 0.4$ & $1.92 \pm 0.7$ \\
\hline $\mathrm{V}_{0}$ & $1.2 \pm 7.3$ & $3.6 \pm 7.9^{*}$ \\
\hline $\mathrm{EDP} / \mathrm{VR}\left[\mathrm{k}_{1}\right]$ & $0.12 \pm 0.06$ & $0.10 \pm 0.07 \dagger$ \\
\hline SW/EDVR [R(s)] & $0.14 \pm 0.08$ & $0.18 \pm 0.08^{*}$ \\
\hline $\mathrm{SW} / \mathrm{EDPR}[\mathrm{R}(\mathrm{t})]$ & $0.22 \pm 0.15$ & $0.34 \pm 0.19 \dagger$ \\
\hline
\end{tabular}

All values are mean \pm standard error of the mean. $L H B(-)$, Without left heart bypass; $L H B(+)$, with left heart bypass; $E \max$, slope of maximum elastance; $V_{o}$ volume intercept of Emax; $E D P / V R$, end-diastolic pressure volume relation; $k_{I}$, slope of end-diastolic pressure/volume relation; $S W$ $E D V R$, stroke work/end-diastolic volume relation; $R(s)$, slope of stroke work/end-diastolic volume relation; $S W / E D P R$, stroke work/end-diastolic pressure relation; $R(t)$, slope of stroke work/end-diastolic pressure relation.

$* p<0.05$ with paired $t$ test between LHB $(-)$ and LHB $(+)$.

$\dagger p<0.01$ with paired $t$ test between LHB ( -$)$ and LHB (+).

was well fitted to the exponential curve $\left(r^{2}=0.74\right.$ to 0.99 , mean $0.95 \pm 0.05)$, and the slope $\mathrm{k} 1$ decreased significantly from $0.12 \pm 0.06$ to $0.10 \pm 0.07$ ( $p<$ 0.01). As shown in Fig. 4, end-diastolic volume was increased for a given end-diastolic pressure and, furthermore, the increment increased as end-diastolic pressure rose. Thus LHB improved the diastolic compliance of the RV. Fig. 5 shows that stroke work/end-diastolic volume relation was closely fitted to the linear regression $\left(r^{2}=0.60\right.$ to 1.00 , mean $0.88 \pm 0.10)$ and that the slope $\mathrm{R}(\mathrm{s})$ was significantly increased, from $0.14 \pm 0.08$ to $0.18 \pm 0.08 \times 10^{5}$ $\mathrm{erg} / \mathrm{ml}$, with LHB. As shown in Fig. 6, stroke work/ end-diastolic pressure relation was fitted to the linear regression $\left(r^{2}=0.54\right.$ to 0.96 , mean $0.82 \pm$ 0.12 ), and the resultant slope, $R(t)$, was significantly increased, from $0.22 \pm 0.15$ to $0.34 \pm 0.19 \times 10^{5}$ $\mathrm{erg} / \mathrm{mm} \mathrm{Hg}$. Consequently, we concluded that LHB improved the overall RV function, particularly at higher end-diastolic pressures.

\section{Discussion}

This study demonstrated that not only the diastolic properties but also the systolic properties of $\mathrm{RV}$ function in postischemic hearts are improved by LHB, with significant recovery of overall RV performance. With regard to potential hemodynamic interactions of RV function during LHB, the following four hypotheses have been considered ${ }^{6}$ : improvement in $\mathrm{RV}$ diastolic compliance resulting from ventricular septal shifting; decrease in $R V$ afterload, which results from reduction in left atrial pressure; increase in preload of the RV; and loss of LV systolic interaction by decompression of the LV.
The former two factors are thought to be beneficial to RV function and the latter two, detrimental.

In our postischemic model, four load-independent RV function parameters were assessed. Of these, end-diastolic pressure/volume relation, which reflects diastolic performance, significantly improved during LHB. This improvement in RV diastolic compliance can be accounted for by the change of RV configuration resulting from ventricular septal shifting to the left. Stroke work/enddiastolic volume relation, the systolic performance parameter, also increased during LHB; this increase was due to reduction in afterload, which would decrease end-systolic volume and thereby increase stroke volume. Consequently, the significant increase in stroke work/end-diastolic pressure relation indicates improvement of the overall performance of the RV as a result of LHB.

In previous studies, however, Miyamoto, ${ }^{12,13}$ Yada, ${ }^{14}$ and their associates found depression of RV contractile function during LHB by assessing factors such as ejection fraction in normal heart models. On the other hand, Elbeery and colleagues ${ }^{15}$ have recently reported that the $\mathrm{RV}$ energetic function during LHB was maintained and that direct systolic interaction with the $\mathrm{LV}$ was of minimal importance in the maintenance of systolic RV function, at least in the normal heart. Farrar, ${ }^{16}$ Chow, ${ }^{17}$ and their associates also reported that the slopes of the Emax and stroke work/end-diastolic volume relation did not change in the normal heart. Fukamachi and coworkers $^{18}$ concluded that the slope of Emax is slightly decreased by LHB in the normal heart and that the overall RV performance is improved owing to good compliance. In experimental models other than LHB, in which the systolic function and systolic interaction between contralateral ventricles were examined, it was reported that the systolic function of the RV was reduced when the LV was decompressed, ${ }^{19,20}$ whereas other investigators have observed no difference in RV function. ${ }^{21}$

These conflicting results may be mainly accounted for by the variety of methods used to assess RV volume, which has not been directly measured volumetrically. Because the RV has complex geometry and contraction patterns, the change of $R V$ volume has remained difficult to assess, even though many investigators have applied various methods, including sonomicrometry, two-dimensional echocardiography, and cineventriculography. These modalities are inadequate to accurately measure the overall RV volume change, because they provide only a 


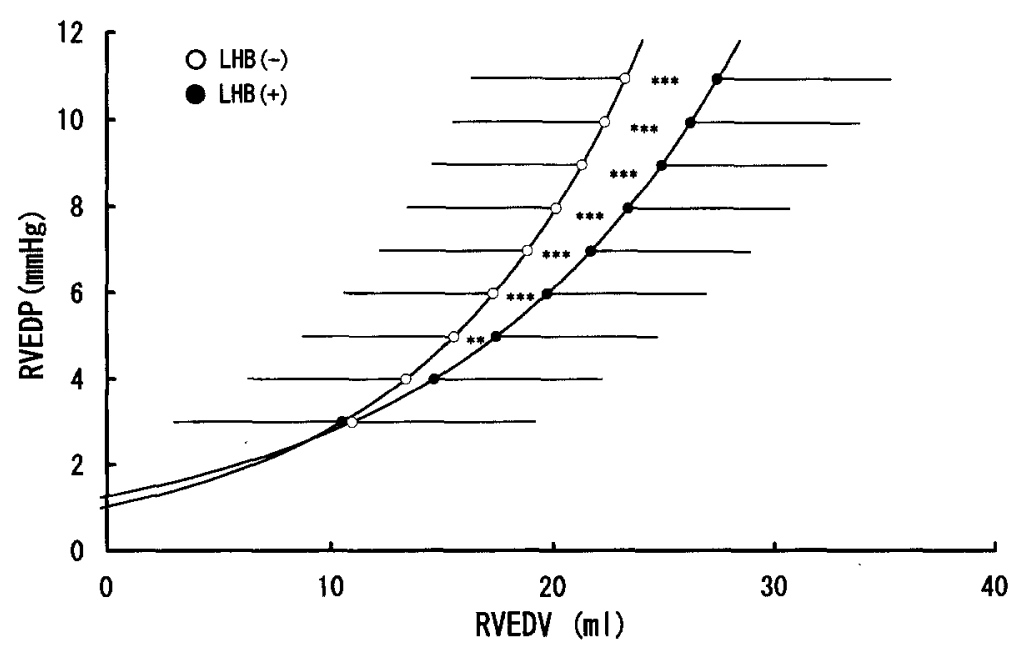

Fig. 4. End-diastolic pressure/volume relations of the right ventricle: End-diastolic volume is averaged at each given end-diastolic pressure. $L H B(-)$, Without left heart bypass; $L H B(+)$, with left heart bypass; $R V E D P$, right ventricular end-diastolic pressure; $R V E D V$, right ventricular end-diastolic volume. ${ }^{*} p<$ $0.05 ; * * p<0.02 ; * * * p<0.01$.

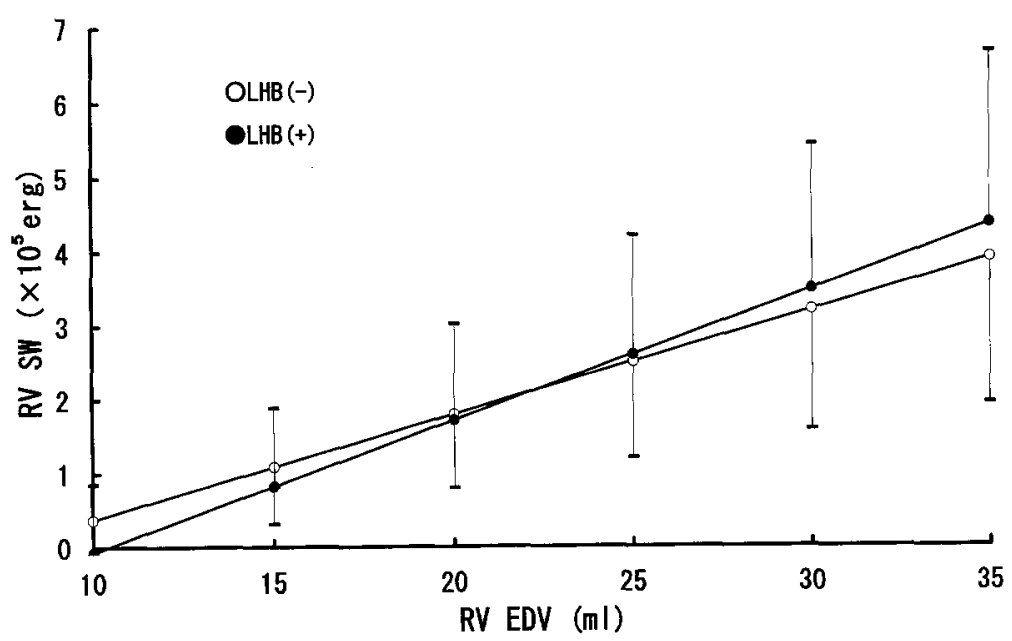

Fig. 5. Stroke work/end-diastolic volume relations: Stroke work is averaged at each given end-diastolic volume. $L H B(-)$, Without left heart bypass; $L H B(+)$, with left heart bypass; $R V E D V$, right ventricular end-diastolic volume; RVSW, right ventricular stroke work.

distance or area value and not a three-dimensional value. Recently, Baan, ${ }^{10,11}$ Burkhoff, ${ }^{22}$ and their colleagues introduced a method whereby LV volume could be estimated by measurement of intraventricular conductance with a specially designed catheter. We then used this catheter to evaluate RV volume. The absolute RV volume derived by this method may not be accurate, because this catheter is designed for the LV, which has an ellipsoid shape. In our study, nevertheless, good correlation was observed between the stroke volume derived from the conductance and that calculated from the elec- tromagnetic flow probe data. In addition, stroke work/end-diastolic volume relation showed high linear correlation, which suggests that this variable accurately reflect the relative changes of $\mathrm{RV}$ volume. Glower and coworkers ${ }^{23}$ demonstrated the linearity of the stroke work/end-diastolic volume relation. Thus we presumed that this method provides reliable analysis of $\mathrm{RV}$ function.

We previously performed similar measurements in normal canine hearts (unpublished data). During LHB, the slope of Emax was slightly decreased, whereas the slopes of stroke work/end-diastolic vol- 


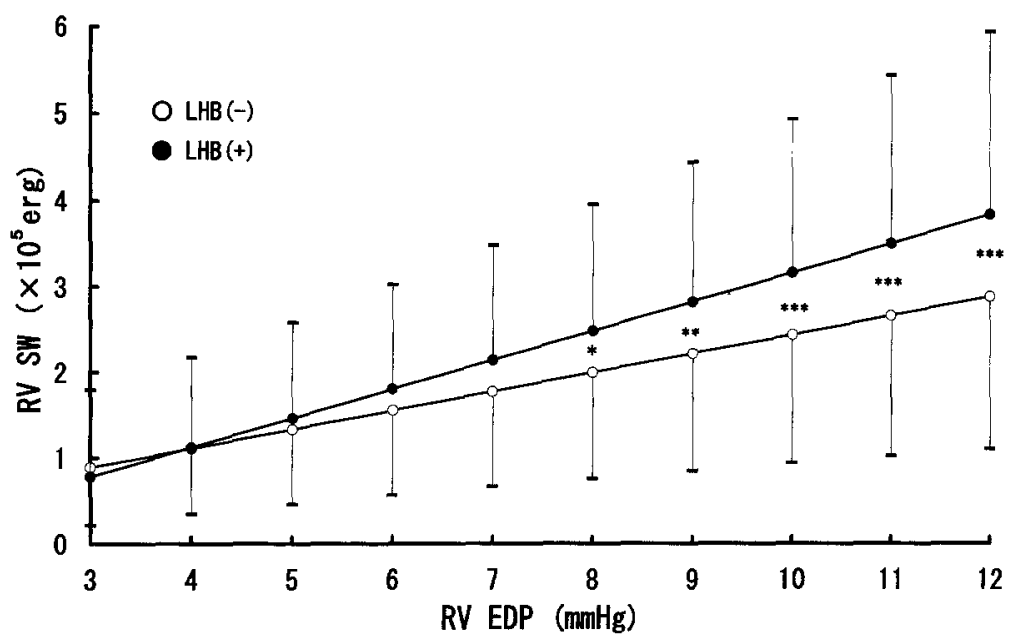

Fig. 6. Stroke work/end-diastolic pressure relations: Stroke work is averaged at each given end-diastolic pressure. $L H B(-)$, Without left heart bypass; $L H B(+)$, with left heart bypass; $R V E D P$, right ventricular end-diastolic pressure; $R V S W$, right ventricular stroke work. ${ }^{*} p<0.05$; $^{*} p<0.02{ }^{* * *} p<0.01$.

ume relation and end-diastolic pressure/volume relation were not changed but only shifted downward and rightward, respectively, and stroke work/enddiastolic pressure relation (total performance) did not change significantly. In the postischemic model, however, the effect of septal shift resulting from LV decompression with LHB is more evident than in the normal heart. The increase in systolic performance, expressed by stroke work/end-diastolic volume relation, is more pronounced in the postischemic model, because the decrease in RV afterload during LHB may be more effective than that in normal hearts. In a comparable clinical study ${ }^{24}$ acute LV unloading resulted in significant improvement of RV function in patients with poor $\mathrm{LV}$ function. In another study, ${ }^{25} \mathrm{RV}$ function was unchanged during LHB in pigs with acute RV ischemia. On the other hand, Chow and $\mathrm{Farrar}^{26}$ reported that LHB impaired RV function in pigs with congestive heart failure. Considering these contradictory reports, we suspect that long-term elongation of RV muscle resulting from congestive heart failure might impair the RV diastolic compliance and that afterload reduction in the RV during LHB would not be effective during prolonged pulmonary congestion.

This study demonstrates that LHB has a beneficial effect on RV function by increasing diastolic compliance and systolic performance and that LHB improves the overall RV function, particularly at higher end-diastolic pressures, in postischemic cardiac dysfunction.
We acknowledge the technical assistance of $\mathrm{T}$. Iwamoto, K. Otsuru, and M. Iwata for carrying out these studies. We also thank E. Hatanaka for secretarial assistance.

\section{REFERENCES}

1. Dennis C, Carlens E, Senning A. Clinical use for left heart bypass without thoracotomy: experimental protection against fibrillation by left heart bypass. Ann Surg 1962;156:623-37.

2. Pae WE, Pierce WS, Pennock JL, Campbell DB, Waldhausen JA. Long-term result of ventricular assist pumping in postcardiotomy cardiogenic shock. $\mathbf{J}$ THOrac Cardiovasc Surg 1987;93:434-41.

3. Pennington DG, Merjavy JP, Swartz MT, William VL. Clinical experience with a centrifugal pump ventricular assist device. Trans Am Soc Artif Intern Organs 1982;28:93-9.

4. Pennock JL, Pierce WS, Campbell DB. Mechanical support of the circulation followed by cardiac transplantation. J THORAC CARDIOVASC SURG 1986;92:9941004.

5. Farrar DJ, Compton PG, Dajee H, Fonger JD, Hill JD. Right heart function during left heart assist and the effect of volume loading in a canine preparation. Circulation 1984;70:707-16.

6. Farrar DJ, Compton PG, Hershon JJ, Fonger JD, Hill JD. Right heart interaction with the mechanically assisted left heart. World J Surg 1985;9:89-102.

7. Pennington DG, McBride LR, Kanter KR, et al. Bridging to heart transplantation with circulatory support device. J Heart Transplant 1989;8:116-23.

8. Portner PM, Oyer PE, Pennington DG, et al. Implantable electrical left ventricular assist system: bridge to 
transplantation and the future. Ann Thorac Surg 1989;47:142-50.

9. James JM III, Gary LP, Charles EM, David RS, Lacques PG, Andrew SW. Quantification of the contractile response to injury: assessment of the worklength relationship in the intact heart. Circulation 1987;76:717-27.

10. Baan Y, Velde ET, Bruin HG, et al. Continuous measurement of left ventricular volume in animals and humans by conductance catheter. Circulation 1984; 70:812-23.

11. Baan Y, Velde ET. Sensitivity of left ventricular end-systolic pressure-volume relation to type of loading intervention in dogs. Circ Res 1988;62:1247-58.

12. Miyamoto AT, Tanaka S, Matloff JM. Effect of left heart bypass on right ventricular function. Trans Am Soc Artif Intern Organs 1982;28:543-5.

13. Miyamoto AT, Tanaka S, Matloff JM. Right ventricular function during left heart bypass. J THORAC Cardiovasc SuRG 1983;85:49-53.

14. Yada I, Wei CM, Hattori R, et al. Right ventricular function during left heart bypass evaluated by twodimensional echocardiography. Trans Am Soc Artif Intern Organs 1985;31:17-21.

15. Elbeery JR, Owen CH, Savitt MA, et al. Effect of the left ventricular assist device on right ventricular function. J Thorac Cardiovasc Surg 1990;99:809-16.

16. Farrar DJ, Compton PG, Verderber A, Hill JD. Right ventricular end-systolic pressure-dimension relationship during left ventricular bypass in anesthetized pigs. Trans Am Soc Artif Intern Organs 1986;32:27881.

17. Chow E, Farrar DJ. Effect of left ventricular pressure reductions on right ventricular systolic performance. Am J Physiol 1989;257:H1878-85.
18. Fukamachi K, Asou T, Nakamura Y, et al. Effect of left heart bypass on right ventricular performance. $\mathrm{J}$ Thorac Cardiovasc Surg 1990;99:725-34.

19. Maughan WL, Kallman CH, Shoukas A. The effect of right ventricular filling on the pressure-volume relationship of the ejecting canine left ventricle. Circ Res 1981;49:382-8.

20. Woodard JC, Chow E, Farrar DJ. Isolated ventricular systolic interaction during transient reductions in left ventricular pressure. Circ Res 1992;70:944-51.

21. Maughan WL, Sunagawa K, Sagawa K. Ventricular systolic interdependence: volume elastance model in isolated canine heart. Am J Physiol 1987;5:H1381-90.

22. Burkhoff D, Velde E, Kass D, Baan J, Maughan WL, Sagawa K. Accuracy of volume measurement by conductance catheter in isolated, ejecting canine heart. Circulation 1985;72:440-7.

23. Glower DD, Spratt JA, Snow ND, et al. Linearity of the Frank-Starling relationship in the intact heart: the concept of preload recruitable stroke work. Circulation 1985;71:994-1009.

24. Farrar DJ, Compton PG, Hershon J, Hill JD. Right ventricular function in an operating room model of mechanical left ventricular assistance and its effects in patients with depressed left ventricular function. Circulation 1985;72:1279-5.

25. Farrar DJ, Chow E, Compton PG, Foppiano L, Woodward J, Hill JD. Effect of acute right ventricular ischemia on ventricular interactions during prosthetic left ventricular support. J THORAC CARdiovasc Surg 1991;102:588-95.

26. Chow E, Farrar DJ. Right heart function during prosthetic left ventricular assistance in a porcine model of congestive heart failure. J THORAC CARDIOVASC SURG 1992;10:569-78. 